\title{
USE OF NUTRITIONAL SUPPLEMENTS BY MALE GRECO-ROMAN WRESTLERS
}

\author{
Dilyana Zaykova, Lubomir Petrov, Albena Alexandrova \\ National Sports Academy "Vassil Levski"
}

\begin{abstract}
Introduction: Wrestling is a strength sport which requires specialized training exercises successfully combined with an adequate nutritional regime and periods of recovery.

Methodology: We surveyed 24 male Greco-Roman-style wrestlers of various weight categories with an average age of 23.2 years and an average sports experience of 10.5 years, performing an average of 9.6 workouts per week. The wrestlers have won prizes at European, World and National Championships.

The subjects completed a diet-assessment questionnaire developed by us, which included 28 questions about their weekly consumption of basic food products and questions about age, training experience, the number of training sessions per week, height and weight. They had also completed a questionnaire on their use of nutritional supplements, including 18 questions about the sources of information, resources, the type and amount of vitamins, proteins, amino acids and other supplements.

Results: The wrestlers' primary source of information regarding nutritional supplements were their coaches as well as Internet. 67\% of subjects used whey protein, which provides an average of $0.42 \mathrm{~g}$ of extra protein per kilogram of body weight. Twenty-two of the participants in the survey used amino acids. Fourteen people have indicated the additional use of BCAAs, the rest combined BCAAs with glutamine, other essential or complex amino acids. Certain individual athletes achieved the recommended protein intake only through a balanced diet, even without the use of supplements. For some, however, the intake of BCAAs and creatine was above the recommended. A total of nine of the wrestlers were taking creatine. Multivitamins were taken by $64 \%$ of the competitors, and B-complex and vitamin $C-$ by $22 \%$ and $7 \%$, respectively. Conclusions: Athletes with a lower than the optimal protein intake for their sport must increase the consumption of foods with high protein content.
\end{abstract}

Key words: wrestling, nutrition, nutritional supplements, BCCAs, creatine

\section{Introduction}

Fighting is a strength sport with weight categories characterized by high intensity and short duration of combats (Erkal, 2015). Fighting develops different functional qualities: muscle strength, flexibility, and neuromuscular coordination, static and dynamic equilibrium (Basar et al, 2014). Good sporting form could be achieved through special training exercises, combined with adequate nutritional regime and recovery periods.

Of great importance is the optimal combination of the three groups of nutrients (proteins, carbohydrates and fats) that effectively provide the basic needs of the organism (Mcardle et al, 2001).

With the progress of the training experience, there is a need for a faster and more efficient recovery process for achievement of higher muscle hypertrophy and strength indicators (Aoi et al,2006). Along with the application of an adequate diet depending on the sports type, there is also a need for additional intake of dietary supplements. Their use is indispensable for enhancing athletic performance and, at the same time, for injury prevention (Campbell, Kreider, 2007).
The purpose of this study was to assess the role of dietary supplements for the quality of the male Greco-Roman-style wrestlers' diet as an important factor in their sports training.

The tasks of the study were:

1. To conduct a nutrition survey with male Greco-Roman-style wrestlers.

2. To conduct a survey on the admission of nutritional supplements with the same group of male Greco-Roman-style wrestlers.

3 . To evaluate the quantity and quality of the supplements as a factor in the nutrition and recovery regime of the competitors.

Hypothesis: The optimal intake of dietary supplements is an important factor for the quality of the nutritional diet of wrestlers.

Methodology: Twenty-four male Greco-Roman-style wrestlers of various categories were investigated. Their average age was 23.2 years. They had an average sporting experience of 10.5 years and during the study they performed an average of 9.6 workouts per week. The contestants have won prizes at the European, World and Republic Championships. 
The surveyed men completed a nutrition assessment questionnaire developed by our research group and applied in a number of previous studies with various contingents (Kolimechkov et al, 2016). This questionnaire included 28 questions about the weekly use of basic food products and questions about age, sporting experience, the number of training sessions per week, weight and height.

The wrestlers completed also a second questionnaire on the use of nutritional supplements, which included 18 questions about the sources of information, the type and amount of vitamin, protein and amino acid supplements. This questionnaire has been developed by the authors especially for the purposes of this study.

\section{Results and analysis}

According to the results, the surveyed wrestlers received information on nutritional supplements mainly from their coaches (37\%) and internet (23\%). The other relied on friends $(17 \%)$, other competitors (13\%) or "other sources" (10\%) (Figure 1). These data showed the leading role of coaches in formation of the supplements' regimen of contestants.

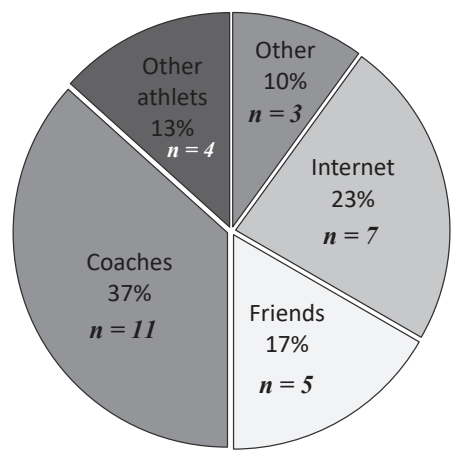

Fig. 1. Sources of information on nutritional supplements. The number of answers exceeded the number of people surveyed because in some cases more than one answer was given.

Of the athletes surveyed, $67 \%$ said that they were using whey protein. This protein gave them an average of $0.42 \mathrm{~g}$ of protein per kilogram of body weight. Eight of the people surveyed took protein only during the preparatory period. One contestant responded that he takes protein in the pre-competition period and one contestant - in the competition period. The other six wrestlers included whey protein in the course of its year-round sports training.

Figure 2 shows the individual relative protein in- take for each competitor obtained both from the food and from the supplements. Considering the extremely intense workload, it could be assumed that the optimum protein intake in combat wrestlers was close to the upper recommended limit of $2 \mathrm{~g} / \mathrm{kg}$ (Campbell, Kreider, 2007), (Kreider, 2004]. Moreover, the calculated average protein intake of the whole group was $2.1 \mathrm{~g} / \mathrm{kg}$.

With regard to protein intake, three groups of athletes were outlined: 1) 8 athletes with much higher than the optimal intake (over $2.5 \mathrm{~g} / \mathrm{kg}$ ), as it should be taken into account the opinion of some authors that in some strength sports even un intake of 2.5$3.0 \mathrm{~g} / \mathrm{kg}$ could be considered as normal (Tripton, Wolfe, 2004);2) 9 athletes with an intake of around $2 \mathrm{~g} / \mathrm{kg}(1.5-2.5 \mathrm{~g} / \mathrm{kg})$, as the athlete № 15 achieved an optimal intake of $2.2 \mathrm{~g} / \mathrm{kg}$ without any supplements; 3) 7 contestants with an intake far below this accepted for optimal. In this group, only two fighters reported an intake of supplement in very low doses.

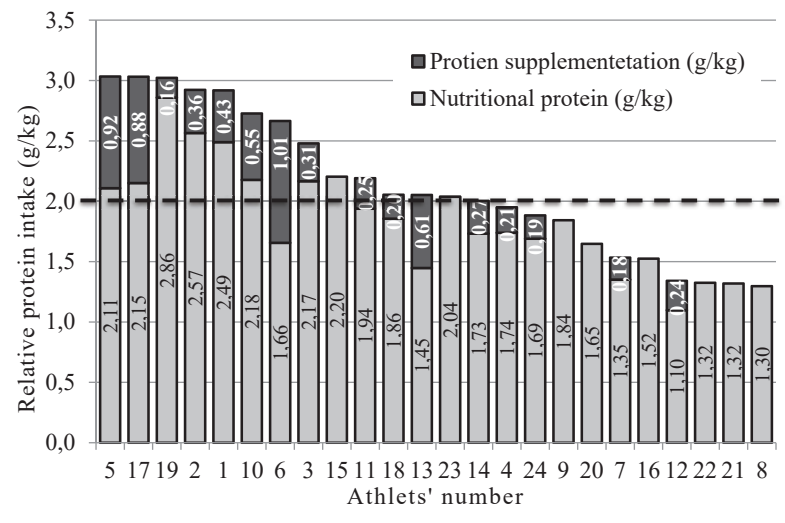

Fig. 2 Relative daily intake of proteins with both food and nutritional supplements in the investigated wrestlers. The dashed line shows the upper limit of the recommended relative intake of protein $-2.0 \mathrm{~g} / \mathrm{kg}$.

Twenty-two of the persons surveyed reported amino acids supplementation. Fourteen of them indicated the additional intake of branches chain amino acids (BCAA) mainly during the preparatory period and six of them have taken BCAA throughout the year. Two wrestlers have taken complex amino acids. Intake of a combination of BCAA and Glutamine has been shown by three people, BCAA and essential amino acids (EAA) - by one person, BCAA, Glutamine and complex amino acids - by one and BCAA, Glutamine, EAA - again by one person (Figure 3). Half of the subjects' athletes took amino acids throughout the year $(\mathrm{n}=11)$ and the others - only in either the preparatory $(n=7)$ and 
competitive $(n=4)$ periods. It has been shown positive effects of $5 \mathrm{~g}$ BCAA supplementation before and after the exercise load (Shimomura, 2004).

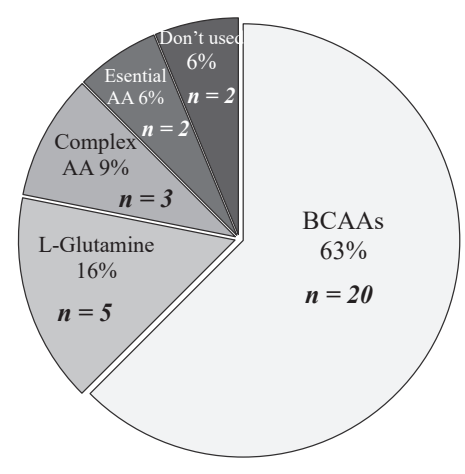

Fig. 3. The Amino Acid supplementation by the survived wrestlers. The number of answers exceeds the number of people surveyed because in some cases more than one answer was given.

A total of 9 people of the tested athletes have taken creatine supplementation: two of them have intake $5 \mathrm{~g}$ only before the workout, three wrestlers $-10 \mathrm{~g}$ only after completion, two wrestlers - an average of $7.5 \mathrm{~g}$ before and after training and two others indicated that they have consumed, on average 5 grams not only in the training days but also in the days without training. Five wrestlers noted that they have taken creatine during the preparatory period, two - during a pre-competitive period and two throughout the year (Figure 4). In the specialized literature the creatine intake includes the following scheme: an initial saturation dose of $20 \mathrm{~g}$ per day or $0.3 \mathrm{~g} / \mathrm{kg}$ divided into 4 intakes per day for a period of one week and a subsequent sustained maintenance intake of $3-5 \mathrm{~g}$ or $0.03 \mathrm{~g} / \mathrm{kg}$ (Cooper et al, 2012).

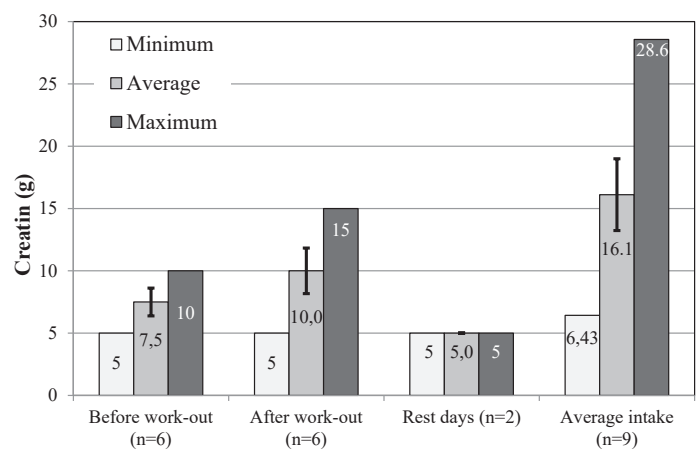

Fig. 4. Creatine supplementation of the tested wrestlers.

The number of answers exceeds the number of people surveyed, because in some cases there was more than one answer.

In regard to vitamins, the multivitamin supplements were the most often mentioned (64\%) by the surveyed wrestlers, and a large number of the contestants have taken them throughout the year. The B-complex vitamins were taken by $22 \%$ of the survived persons. These vitamins were also taken yearround by the most athletes, and only some of them included B-complex vitamins periodically during the preparatory or competition period. Only $7 \%$ of the persons surveyed included Vitamin $\mathrm{C}$ it in their year-round preparation (Figure 5).

Studies have found that athletes involved in heavy workloads may need larger amounts of vitamins such as thiamine, riboflavin and $\mathrm{B} 6$, which are actively involved in the catabolism of carbohydrates and fat in energy production. Also, vitamin B12 is essential for the hemoglobin synthesis, which is the major factor in the delivery of oxygen to muscles during aerobic workloads (Manore, 2001). Many authors recommend these needs to be covered by increased intake of nutrients, although other studies have found vitamin deficiency despite these recommendations. These are mainly reported in weight category sports, where the periodic reduction in body weight is required. The use of vitamin supplements in athletes favors the removal of harmful effects resulting from exercise stress and inadequate intake of essential nutrients (Manore, 2001). The antioxidants vitamins $\mathrm{C}$ and $\mathrm{E}$ prevent cellular and subcellular structures from oxidative damage and thus can optimize the training process. However, it should be noted that pro-oxidants generated during exercise serve as a "signal" for the activation of several cell signaling mechanisms important for optimal physiological function (Droge, 2002).

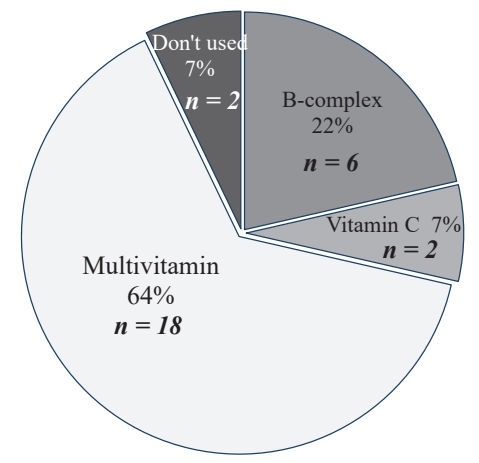

Fig. 5. Vitamin supplementation of the tested wrestlers. The number of answers exceeds the number of people surveyed, because in some cases there was more than one answer.

\section{Conclusion:}

The responses to the survey showed the leading role of coaches in developing a strategy for the nutri- 
tional supplements intake in wrestlers. A low protein intake (below the lower limit of the optimal 1.5 $\mathrm{g} / \mathrm{kg}$ ) was observed even in highly qualified class competitors (in about one-quarter of such cases). A balanced diet could achieve the recommended protein intake even without the use of supplements. The intake of BCAA in some of the contestants significantly excessed the recommendations in the literature. None of the creatine administration mode, applied by the investigated athletes was consistent with the literature described methodologies.

\section{References:}

Almada et al., ISSN Exercise and Sport Nutrition Review: Research and Recommendations, Journal of the International Society of Sports Nutrition, 1(1),1-44, 2004.

Aoi, W., Naito, Y., Yoshikawa, T., Exercise and functional foods, Nutrition Juornal, 5 (15), 2006

Basar, S., Duzgun, I., Guzel, NA., Cicioğlu, I., Celik, B., Differences in strength, flexibility and stability in freestyle and Greco-Roman wrestlers., 27(3):321-30, 2014

Campbell, B., Kreider, R., International Society of sports nutrition position stand: protein and exercise, Journal of the International Society of Sports Nutrition 2007, 4:8doi:10.1186/1550-2783-4-8

Cooper, R., Naclerio, F., Allgrove, J. and Jimenez, A., Creatine supplementation with specific view to exercise/ sports performance: an update, J Int Soc Sports Nutr, 9, 33, 2012

Droge W: Free radicals in the physiological control of cell function. Physiol Rev 2002, 82(1):47-95] and therefore for achieving high sports results.

Erkal Arslanoglu, Physical profiles of Turkish young
Greco-Roman wrestlers, Academic Journals, Vol.10(8), pp. 1034-1038, April 2015

Kolimechkov, S., Petrov, L., Alexandrova, A., and Atanasov, P., Nutrition and physical development assessment of pre-school and primary school children practicing artistic gymnastics, African Journal for Physical Activity and Health Sciences (AJPHES), 22 (2:2), 565577, 2016

Manore M. Vitamins and minerals: Part I. How much do I need? ACSM's Health \& Fitness Journal, 5, 33-35, 2001

Mcardle, W., Katch, F., and Katch, V., Exercise physiology-energy, nutrition and human performance, Williams \& Wilkins, 1996

Shimomura, Y., Murakami, T., et al., Exercise Promotes BCAA Catabolism: Effects of BCAA Supplementation on Skeletal Muscle during Exercise, The American Society for Nutritional Sciences J. Nutr., 134, 1583-1587, 2004

Tripton, K., Wolfe, R., Protein and amino acids for athletes, Journal of Sports Sciences, 22, 65-79, 2004

Dilyana Zaykova

NSA "Vassil Levski"

Sofia, 1700

Bul. Academician Stefan Mladenov № 21

Department "Heavy athletics, boxing, fencing and sport for all"

+359899729963; e-mail: dilianazaikova@gmail.com

Lubomir Petrov

National Sports Academy "Vassil Levski"

Department of "Physiology and biochemistry"

Albena Alexandrova

National Sports Academy "Vassil Levski"

Department of "Physiology and biochemistry" 